\title{
Chinese and Japanese Characters from the Perspective of Multimodal Studies
}

\author{
By Nadiia Kirnosova $^{*}$ \& Yuliia Fedotova ${ }^{ \pm}$
}

\begin{abstract}
This article aims to demonstrate that a character can generate at least three different modalities simultaneously - visual, audial and vestibular - and influence a recipient in a deeper and more powerful way (than a sign from a phonetic alphabet). To show this, we chose modern Chinese and Japanese characters as live signs, and analyzed them functioning in texts with obvious utilitarian purposes - in advertisements. The main problem we were interested in during conducting this research was the "information capacity" of a character. We find out that any character exists in three dimensions simultaneously and generates three modalities at the same time. Its correspondence with morphemes opens two channels for encoding information - first of all, it brings a space for audial modality through the acoustic form of a syllable, and then it opens a space for visual modality through the graphical form of a character. The latter form implies a space for vestibular modality, because as a "figure," any character occupies its "ground" (a particular square area), which becomes a source of a sense of stability and symmetry, enriching linguistic messages with non-verbal information.
\end{abstract}

Keywords: advertisement, character, information, mode, multimodality

\section{Introduction}

Multimodal studies is a research field that has emerged in recent years and generated a great interest across different disciplines. Modern societies all across the world are preoccupied with the possibilities new digital media give them to deal with information at different levels (modes) at once. It seems to be especially interesting to study texts written in characters from this perspective, as these writing signs, when perceived and interpreted by a recipient, activate more than one channel of processing information in our mind, so any character can be studied as a potential source of several different modes of organization of information. This article aims to demonstrate that characters can generate simultaneously at least three different modalities - visual, audial and vestibular, and influence a recipient in a deeper and more powerful way, than a sign of a phonetic alphabet.

To show this, we chose modern Chinese and Japanese characters as live signs, circulating in two very populous countries in the world, and analyzed them functioning in texts with obviously utilitarian purposes - in advertisements. We kept in mind that Japanese characters were borrowed from China, so speaking about Chinese and Japanese characters we are actually speaking about one writing

\footnotetext{
*Associate Professor, Taras Shevchenko National University of Kyiv, Ukraine.

${ }^{ \pm}$Lecturer, Taras Shevchenko National University of Kyiv, Ukraine.
} 
system. We also know that some signs were created by Japanese people themselves, though based on Chinese elements and structures, and these signs were a major point of our interest in Japanese characters in this article. As we guessed, they would help us to reveal some universal characteristics of characters with multimodality among them, thus is why we decided to study both types of writing in comparison.

So, let us look at these old signs from a new point of view. The first thing to say about the Chinese writing system is that it has a long history - as long as 5,000 years. The earliest known record of Chinese characters comes from oracle bones during the Shang Dynasty (which ruled in the XVIII century before Christ). As this history was never interrupted, the Chinese writing system is considered to be the oldest living one in the world, and Chinese characters have been utilized for over four thousand years (Hanzi 2009, p. 8). Another thing to mention is the figurative nature of its signs: they come from pictures, and even in highly stylized modern versions the characters still remain images, not pure symbols. This latter characteristic marks the main difference between the phonetic writing systems of Western languages, and the Chinese one. Due to this figurative property, Chinese characters may be interesting in the context of multimodality studies, as these characters are images, acoustic recordings (and linguistic) units.

According to the famous historian J. Friedrich, Japan did not have its own writing before the introduction of characters. Japanese scholars also share this view, based on the fact that until now no written sources have been found that would indicate the existence of writing in ancient Japan (Doblhofer and Friedrich 2002, p. 48).

It is believed that Chinese characters first caught the eye of the Japanese in the form of engravings on metal utensils, coins and gold seals, which Chinese rulers gave to Japanese ambassadors. At that time, trade with China and the ancient Korean state of Pekche revived significantly. Products of Chinese craftsmen were imported to Japan, but the Japanese perceived hieroglyphic inscriptions only as beautiful patterns. First, they simply imitated these "ornaments" for decorating ceramic tableware. As the process of unification of the country went on, and along with the strengthening of trade and economic ties with foreign countries, there was a need to create writing. The choice in favor of Chinese characters was due to the territorial proximity of the two countries and China's unconditional leadership on the geopolitical map of Asia.

Beginning from the 6th century, Buddhist books written in Chinese began to actively penetrate Japan. The Japanese often traveled to China to learn Chinese science and the structure of social life. With the spread of Buddhist literature and the emergence of monasteries, the Chinese language attracted more and more attention. Its status resembled that of Latin in medieval Europe. Later Chinese characters were used as a basis for creating a unique Japanese writing - a phonetic alphabet called kana. At present, writing in Japan functions in 4 different ways: characters, including kokuji - those invented by Japanese themselves; hiragana phonetic alphabet for words of native Japanese origin and flexions grammatical inflection; katakana - phonetic alphabet for borrowed lexis; and romaji - Latin alphabet. Studies on the multimodality of Japanese writing are first of all based on 
different ways of transmitting information through these writing systems and influencing the recipient of the visual message.

We chose advertisements written in characters to demonstrate an effect of multimodality, because these texts are created to influence a recipient. The main problem we were interested in during conducting this research was the "information capacity" of a character. We noticed from our practice of communication that texts written in characters may influence a recipient deeper than texts written in phonetic signs, evoking different emotions and catching your mind in a "trap" of images and associations. Based on this experience, we conclude that these messages are perceived in a specific way and we decided to study the possibilities of characters as very powerful signs for transmitting information. We find this problem very actual because our life is full of messages aimed to influence us, and there is quite an abundance of these messages (advertisements, novels, etc.). Those written in characters, which need to be translated into other languages with noncharacter writing systems, need to be recoded from a highly sophisticated multimodal way of conveying information into a less sophisticated multimodal representation. In this case translators have to know how to shift between different channels of transmitting information, activated in any particular case, and how to use special means to convey the maximum of possible information.

\section{Theoretical Background}

As far as we know, characters have not been studied from a multimodality point of view yet, though the question on how they convey meaning is quite an old one and has more than a 2,000 year history in China and about 1,500 years in Japan. Though characters were studied as information mediums in these traditions, eastern philologists paid attention only to one particular mode of functioning, dominated in conveying meaning from their point of view.

\section{Studies of a Visual Mode}

It can be noted briefly that in China it was $\mathrm{Xu}$ Shen who initiated a tradition of studying characters within the visual mode of conveying meaning by his famous work 〈谽文解字〉 (“Shuo wen jie zi”, “Description of simple signs and explanation of complex signs"), devoted to the character's structure. It was written in I century after Christ, and since then there were other conceptions based on it. It is noteworthy that Japanese researchers of hieroglyphic writing also rely on the classic work of Xu Shen. In the Western tradition this line was followed by Wieger (1965) who used very interesting English equivalents for the Chinese terms, proposed by Xu Shen: 文 he called "simple figures" and 字- “compound letters" (Wieger 1965, p. 10). The term "simple figures" seems to be especially significant in the context of multimodality studies because it represents a character (basic or primitive one) as a visual phenomena (figure) first. For the same reason, the term "imitative drafts" (Wieger 1965, p. 10), which is replaced by the term "pictogram" now, seems to be more informative from the multimodality point of view. The 
detailed analysis of grapho-stylistic functions of Japanese writing is conducted by Y. Mayevskiy - the usage of writing in close relation to the Japanese culture - by V. Alpatov. Both authors describe the visual modality expressed by each type of Japanese writing, i.e., characters, kana and romaji. Mayevskiy also divides graphical stylistics into orthographical and calligraphical means. Orthographical stylistics deals with different types of writing, vertical and horizontal orientation of texts, etc., and calligraphical stylistic means deal with handwriting vs. computer fonts usage and other means of producing texts (Mayevskiy 2000, Alpatov 2003). Rezanenko (1989) is the author of numerous studies in both Japanese and Chinese languages devoted to the problems of the meaning of the graphical system of the Chinese hieroglyphic writing (Rezanenko 1989).

\section{Studies of an Audial Mode}

The acoustic mode of a character was not so popular among scholars in China, but still there were surges of interest in it that were connected to the development of ancient transcription fanqie. It was Wang Zishao, who considered that $a$ phonetic, representing a sound of a word, not a radical, pointing out a category, carries its meaning ( $\mathrm{Xu} 2009)$.

\section{Studies of a Vestibular Mode}

As for vestibular mode of functioning, it was (and it is) rather practiced then studied by Chinese calligraphers from ancient times until present, but some aspects of this mode of communication, like orientation of a text (horizontal or vertical) etc., were taken into consideration in such research by Mayevskiy (2000).

\section{Studies of Multimodal Phenomena}

In Western tradition we can see a great interest to multimodality studies now, but characters are not a point of interest yet. Still, some approaches to the notion "text" in multimodal discourse analysis as a new emerging field of enquiry can be applied to a character, open a way for understanding a character as a text, multimodal by its nature. Such a conclusion comes from Kress's approach, for example: "Texts, of whatever kind, are the result of the semiotic work of design, and of processes of composition and production. They result in ensembles composed of different modes, resting on the agentive semiotic work of the maker of such texts" (Kress 2011, p. 36)

Every word, put in italics by the author of the citation above is applicable for characters, so any of them can be considered as a text and an object of a multimodal discourse analysis, because, as any other text, it is "the material site of emergence of immaterial discourse(s)" (Kress 2011, p. 36).

In Japan the interest in multimodal studies is mainly seen in the works on communicative linguistics and pedagogy. Japanese researchers often use the methodology of Western multimodality studies from the works of Kress, O'Halloran, and others. 
In trying to apply the multimodal discourse analysis to Chinese and Japanese characters, we used key terms of the field as they are defined in A. Lyons' research (Lyons 2016, p. 278). We also agree with the author that, "adopting a multimodal approach to data analysis has clear benefits: Multimodal communication is central to human interactions, and multimodal analysis enables a more systematic insight into how multiple modes are employed in multimodal ensembles to convey complex meanings. Also, social and cultural meanings are often conveyed in modes other than speech and writing. Video data provides a wealth of details for analysis in a durable and sharable form and provides scope for microanalysis of fine-grained detail" (Lyons 2016, p. 276). We find it a good argument to apply the multimodal discourse analysis to the writing communication, using characters.

\section{Cognitive Studies}

A new prospective was opened with the development of cognitive studies and there are some works in China and Japan now, studying a cognitive potential of a character, for example by Zhang (2010) or Guder et al. (2007).

\section{Methodology}

While conducting this research we used the methods of multimodal analysis and cognitive analysis. Applying these methods, we try to reveal a piece of information, conveyed in different modes, and mental peculiarities, which are objectified through these modes. The method of structural analysis was also applied to show possibilities of characters' form and what it tells to our eye.

\section{Visual Mode of a Character}

The source of visual modality of a Chinese character is its shape. To reiterate from above, modern Chinese characters came from pictures, and in the simplest forms they borrow their shapes from material objects in the world, and in more complicated forms characters combine two or more simple forms in particular ways.

The character "rice" (米 Figure 1), for example, is a simple form, while the character "porridge" (粥 Figure 2), was designed on the basis of three simple forms: "rice" + "pot" + "steam" (in the modern version of the character, the element "pot" is eliminated), and, thus, belongs to complex forms. 
Figure 1. The Character "Rice"

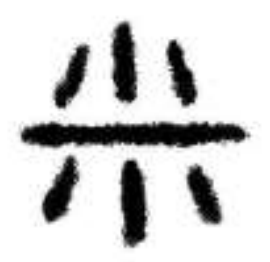

Source:https://gimg2.baidu.com/image_search/src=http\%3A\%2F\%2Fgss0.baidu.com\%2F-4o3dS ag_xI4khGko9WTAnF6hhy\%2Fzhidao\%2Fpic\%2Fitem\%2F3801213fb80e7bec10430d822f2eb93 89b506b33.jpg\&refer $=h t t p \% 3 A \% 2 F \% 2 F g s s 0 . b a i d u . c o m \& a p p=2002 \&$ size $=f 9999,10000 \& q=a 80 \&$ $\mathrm{n}=0 \& \mathrm{~g}=0 \mathrm{n} \& \mathrm{fmt}=\mathrm{jpeg}$ ?sec $=1625596148 \& \mathrm{t}=5620 \mathrm{~d} 5 \mathrm{~b} 2 \mathrm{e} 751 \mathrm{ae} 0 \mathrm{fd} 3 \mathrm{ce} 6 \mathrm{ffb} 10 \mathrm{ea} 690 \mathrm{c}$

Figure 2. The Character "Porridge" (in its Ancient Form)

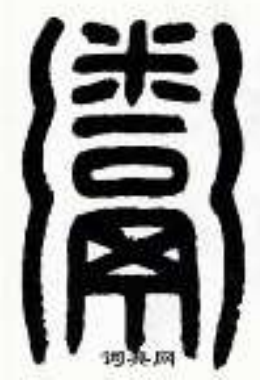

Source:https://gimg2.baidu.com/image_search/src=http $\% 3 \mathrm{~A} \% 2 \mathrm{~F} \% 2 \mathrm{Fc}$.cidianwang.com $\% 2 \mathrm{Ffile} \% 2$ Fshufa\%2Fzhuanshu\%2Ffangquji \%2F2016925161515db508.jpg\&refer=http\%3A\%2F\%2Fc.cidian wang.com\&app $=2002 \&$ size $=f 9999,10000 \& q=a 80 \& n=0 \& g=0 n \& f m t=j p e g ? s e c=1625596363 \& t=85$ f246c4ff55d8fa01f424e77a86212e

It should be stressed here that Chinese characters (neither modern, nor ancient) do not represent (or signify) objects or situations as something material; rather they signify notions of these objects or situations. In particular, simple characters, also called the basic elements of Chinese writing system or pictograms, are schematic representations of concrete concepts, and their shapes come from the generalization of sensory experience in the process of perceiving of the world. Complex characters are schematic representations of abstract concepts and designed on the basis of association. But it is important to stress now, that being schematic representations, these characters remain images.

Now let us see precisely what kind of generalization there is and what kind of information they convey. Let us take some simple signs: the character "rat" (鼠, Figure 3) depicts the notion of a rat as an animal with a thin hairless tail, which eats rice, and these peculiarities make it possible to differentiate it from a horse (马 Figure 4), which has a hairy tail and mane, and from a pig (豕, Figure 5), which has a big body and a mane, also, as well as from a tiger (虎 Figure 6), who has big jaws with sharp teeth. 
Figure 3. The Character "Rat"

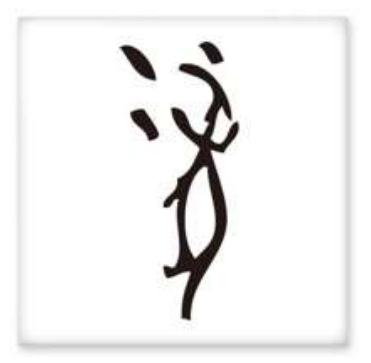

Source:https://gimg2.baidu.com/image_search/src=http\%3A\%2F\%2Fwww.diythinker.cn\%2Fimag e\%2Fcache\%2Fdata\%2Fshare\%2Fsku00302886f19989-cover-600x600.png\&refer=http\%3A\%2 $\mathrm{F} \% 2 \mathrm{Fwww}$.diythinker.cn\&app=2002\&size $=\mathrm{f} 9999,10000 \& \mathrm{q}=\mathrm{a} 80 \& \mathrm{n}=0 \mathrm{\& g}=0 \mathrm{n} \& \mathrm{fmt}=\mathrm{jpeg}$ ? $\mathrm{sec}=162$ 5596580\&t=eb9375eec532189238ea97fa00147e66

Figure 4. The Character "Horse"

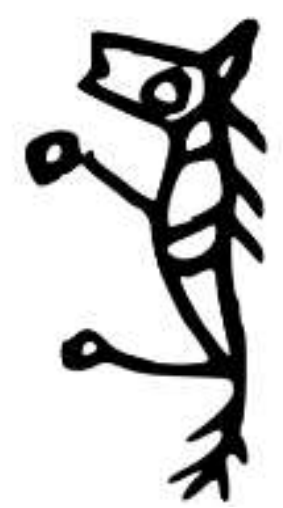

Source: https://gimg2.baidu.com/image_search/src=http\%3A\%2F\%2F5b0988e595225.cdn.sohuc s.com\%2Fimages\%2F20181106\%2F474277b6d22f430a91e87dc966cd1e0e.jpeg\&refer=http\%3 $\mathrm{A} \% 2 \mathrm{~F} \% 2 \mathrm{~F} 5 \mathrm{~b} 0988 \mathrm{e} 595225$.cdn .sohucs.com\&app $=2002 \&$ size $=\mathrm{f} 9999,10000 \& \mathrm{q}=\mathrm{a} 80 \& \mathrm{n}=0 \mathrm{~g} \mathrm{~g}=0 \mathrm{n} \&$ $\mathrm{fmt}=$ jpeg?sec $=1625596675 \& \mathrm{t}=03 \mathrm{a} 268658 \mathrm{de} 3 \mathrm{f} 5 \mathrm{fce} 4 \mathrm{caa} 163 \mathrm{f} 02 \mathrm{f} 3 \mathrm{c} 88$

Figure 5. The Character "Pig"

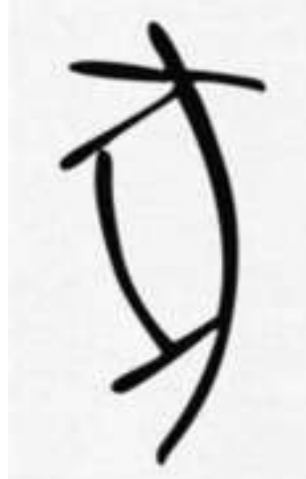

Source: https://gimg2.baidu.com/image_search/src=http $\% 3 \mathrm{~A} \% 2 \mathrm{~F} \% 2 \mathrm{Fwww}$. cnepaper.com\%2Fggr b\%2Fresfile\%2F2019-02-24\%2F03\%2Fp3b.jpg\&refer=http\%3A\%2F\%2Fwww.cnepaper.com\&ap $\mathrm{p}=2002 \&$ size $=\mathrm{f} 9999,10000 \& \mathrm{q}=\mathrm{a} 80 \& \mathrm{n}=0 \& \mathrm{~g}=0 \mathrm{n} \& \mathrm{fmt}=\mathrm{jpeg} ? \mathrm{sec}=1625596911 \& \mathrm{t}=12 \mathrm{c} 0041 \mathrm{c} 53 \mathrm{~b} 8 \mathrm{f} 5$ elf161d3f6423e2bae 
Figure 6. The Character "Tiger"

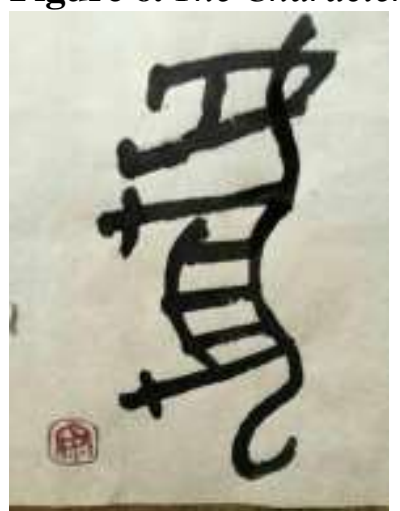

Source: https://ss1.bdstatic.com/70cFuXSh_Q1YnxGkpoWK1HF6hhy/it/u=2318148763,384647 $4554 \& \mathrm{fm}=26 \& \mathrm{gp}=0 . j p g$

We can see that none of these old characters depict signified objects precisely, they are only schemas, or these characters may be called simplified images of objects based on the most vivid features of them, as a type of generalization. As such, they may be considered as visualizations of mental representations of objects, actually as visualizations of concrete concepts, but not necessary in a strict logical sense (like a notion), but in the sense of a prototype, as it is understood in the theory of prototype (they visualize not strict logic concepts, but concepts based on everyday life). This generates images as highly influential from a recipient point of view.

Let us also analyze some complicated characters and see what kind of information they convey. According to the ancient Chinese philologist $\mathrm{Xu}$ Shen, there are three types of characters with complicated structure, but as we stay in the visual mode in this paragraph, we pay attention only to two of them - indicators of function and ideograms - because the third type, phonoideograms, contain phonetic elements and will be analyzed later in the section of acoustic mode.

Let us see an example of indicators of function first. The character "root" (本) was created on the basis of the character "tree" (才) by adding a "pointing mark" $(\rightarrow$ to it in the place, where "root" should be, and stressing this part (root) in the whole (tree).

This mainly refers to the basic characters derived from China, so it is possible to say that the Japanese characters of this type are formed in the same way. Thus it seems to be the next step of abstracting of our thought (on the basis of generalization), which is mirrored in Chinese characters, is a dividing of a whole into parts and stressing one of those parts. This division and highlighting of a part is important for the particular situation to be fixed in signs.

In a more complex illustration, if we analyze the character "family" (家), we can find that it is constructed from two simple elements, creating an association with a particular abstract concept. Characters of this type are called ideograms. The character "family", which shows a pig in a house, is based on a conceptual association: as pigs were very important for maintaining everyday life in ancient China, it was obvious for ancient Chinese people that a pig under a roof pointed out the idea (or abstract notion) of family. Thus, the positioning of some elements 
together in one sign is a way to visualize ideas with the help of association.

There are many names for fish and marine animals among kokuji, which is due to the geographical location of Japan: 鮙 "iwasi" - the name created by the combination of characters 魚/sakana/“fish" and 弱/yowai/ "weak", due to the fact that iwasi dies immediately as soon as it is pulled out of the water; 鱈/tara/ "cod" - fish whose meat is as white as snow (魚 "fish" + 雪 /yuki/ "snow”); 鯱 /shachi/"killer whale" - a predatory marine mammal, “tiger fish" (魚“fish”, 虎 /tora/"tiger"). From the examples above we can see that most of kokuji are either phonoideograms or complex pictograms, which were formed from the already existing pictograms of Chinese origin. But the Japanese, in the process of creating these signs, combined Chinese pictograms in their own way (Obara and Okazawa 2011, pp. 36-37).

It is necessary to stress that two letter types, based on simple schemes-images, are also essentially images. The first one (indicators of function) proposes a "ready-made" result of abstracting, and is very easy to perceive. The second one (ideograms) is easy to remember due to association.

Thus, just as abstract concepts in our mind are formed on the basis of concrete concepts, complex Chinese characters are formed by combining two or more basic characters in the same space. We can consider characters to be a way of visualizing the steps of development of our mind from concrete thought (based on images) to abstract notions. For modality studies of characters, it is interesting to note that all this cognitive information is stored in images, which are not verbal and present concepts of our mind directly, without the help of language; that is why they are easier to grasp, including all levels of information, like cognitive, emotional, modal etc.

This thesis can be illustrated by an example of a social issue ad presented in Figure 7.

Figure 7. Social Issue Ad in Beijing Metro

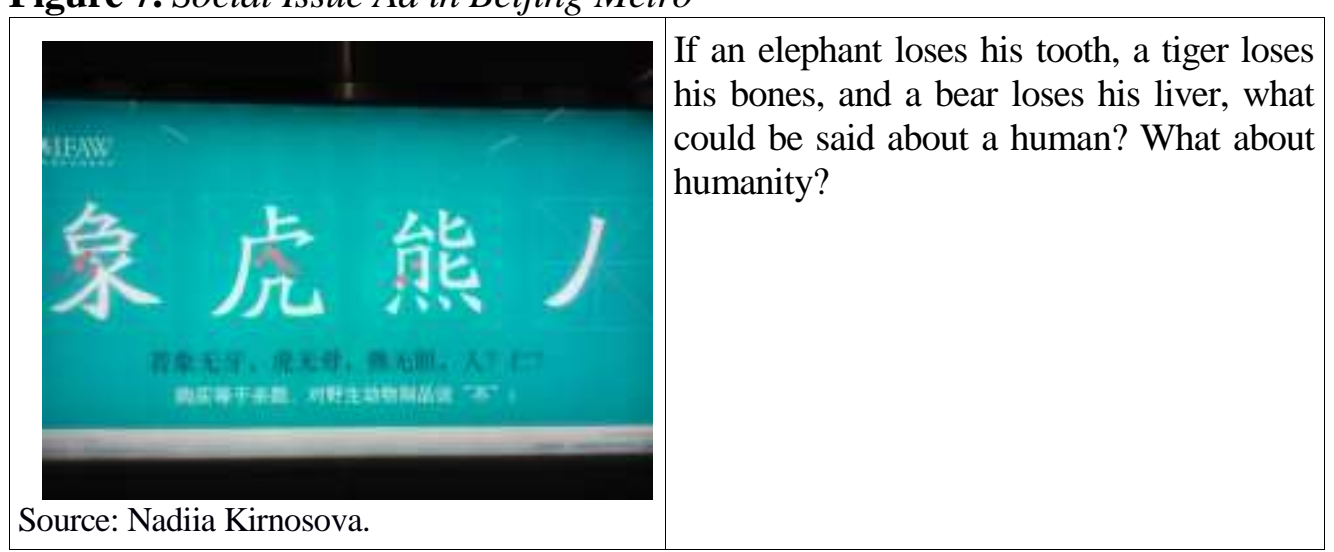

Characters "elephant", "tiger", "bear" are written with blood stains instead of some strokes, representing some parts of their bodies, and a character "human" is written with a "defect" - without a "leg" (it lacks a stroke, also representing a part of its body). It illustrates an idea, that if somebody kills animals with the aim to obtain some of their parts, he/she cannot be called a human. 
In comparison with social issue ads in Western countries, this one does not include pictures, only text, but this text, written in characters, generates powerful images on the basis of forms of these signs, and is more vivid and eloquent by means of graphical metaphor.

So, characters (at least a part of them) are presented in a form of image and convey specific, paralinguistic information for the visual channel, that's why they are more easily grasped and remembered.

\section{Acoustic Mode of a Character}

Three types of structure, mentioned above, corresponds with the traditional notion of character - a sign, which points out meaning, not sound. They would have been enough to write any idea, and the system of Chinese characters might have stopped its development at this stage, but it faced a problem. When the quantity of signs should be equal to the quantity of concepts, this is not very convenient to memorize and use. So the system continued its development and pictophonetic characters were invented, lending characters to sounds. These types of characters also use basic elements (or simplified images) from the first category of signs, but in this case they are linked together not by a semantic association, but by an acoustic one, as a type of rebus. The character "roar" (唬), for example, shows a mouth and a tiger, where the "mouth" (口) means that this word by its meaning belongs to a category of sounds (onomatopoeia), produced by mouth (articulated sounds), and the "tiger" (虎) therefore means that this word sounds like the word "tiger". Thus phonetic helps to conceptualize a meaning in the frame of a particular category.

It is commonly accepted that phonetic does not specify meaning of a character, but it is not necessarily true. There are some characters in Chinese, whose meanings we realize through phonetic, not semantic (although the semantic, as usually, clarify the category, to which that character belongs to). For example, the character 沁 qin, which is used to name a river Qinshui, consists of the semantic water ( $\forall$ ) and the phonetic heart (心xin), which associated with the "capability" of our heart to be "soaked" by intelligent forces (Luo 2011, p. 102). It is not by chance (or not only by mostly similar sounds) used in the name Qinshui, because this river flows through the most fertile lands in China, soaked with its water. In this case the phonetic also helps to conceptualize the meaning of the character 沈inside a category of things somehow connected with water.

We can see that phonetic usually is responsible for conceptualization of the "content" of a character, and semantic, for categorization of it. But now let us say that not only phonetic is a source of acoustic modality in the character.

The main source of audial (or acoustic) modality in characters is a connection between a character and the language unit with which it corresponds. As any character correlates with meaningful groups of sounds and depicts its meaning, it is broadly accepted now among linguists that it corresponds with a morpheme, which is a meaningful (but not independent) combination of sounds, "tied" by tone into a syllable with strict bounds in Chinese language. In this sense, 
any character should be considered as a root morpheme, and although there are auxiliary morphemes in the Chinese language, they were converted from roots by losing their lexical meaning.

The issue of correspondence between Chinese characters and language units was actively discussed during the twentieth century, after the first grammar of the Chinese language was published by Ma Jianzhong in 1989. As the object of that first research was an old literary language called wenyan in which monosyllabic words made up the majority of words, the idea that "one character $=$ one word" was broadly accepted. However in the XX century the famous Chinese-American linguist Zhao Yuanren (also known as Yuen Ren Chao) showed that the correspondence between characters and words may only be functional, not structural, meaning that it is incorrect to say that characters denote words (Zhao 2002, p. 893). This thesis was especially true for researchers who shifted to the modern Chinese language as an object with a majority of disyllabic words, so they started to search for another formula of correspondence until the end of the twentieth century when it became broadly accepted, that "one character $=$ one morpheme"1.

Another point to underline is the strong quantitative correlation between morphemes and syllables ${ }^{2}$ in the Chinese language, namely "one morpheme $=$ one syllable", which were noticed by Ivanov and Polivanov (2007). Now, taking into consideration that "one morpheme = one character," we can build a next formula, which describes the intersection between characters as a graphical unit, and a morpheme as an acoustic unit in the Chinese language: "one character $=$ one morpheme $=$ one syllable".

Depicting the meaning of morphemes (not their pronunciation) is a peculiarity of Chinese characters as letter signs, and that is why they are sometimes called "dumb signs" (especially pictograms and ideograms, less pictophonetic signs). This is not actually true because any Chinese character, through its correspondence with a morpheme and association with pronunciation of this language unit, can be read. It means that Chinese characters do represent the dimension of sounds in processes of communication and transmitting information, not directly - like the letters of phonetic alphabets (as for pictophonetic characters, mentioned above, they do have even this property) — but through its correspondence with a morpheme.

So, the correlation with a language unit (morpheme) opens up a way for Chinese characters to generate an audial modality. Like figures of characters divide the continuum of space into equal squares and organize them in a line (horizontal or vertical - does not matter), syllables, associated with these characters, divide the stream of sounds into equal acoustic units which are

\footnotetext{
${ }^{1}$ There are some words in the modern Chinese language, which consist of two syllables or more (like foreign language words, borrowed by transcription), but are considered to be one morpheme. Nevertheless their part in lexical fund is too small, and they are obviously "alien" for Chinese language, that is why these words cannot influence the formula, mentioned above and accepted in general for the modern Chinese language.

${ }^{2}$ It should be stressed also, that syllable, not phoneme is considered to be the basic unit on phonetic level in the Chinese language.
} 
characterized by clear boundaries. All sounds in one syllable are "tight" by tone and "gravitate" to that vowel, which carries it (tone), like to the certain center of the syllable. Thus there is no ambiguity in cutting the stream of sound in Chinese speech into separate syllables; they are always very obvious and easy to identify.

It is difficult to say now if this phonetic structure determines such a great affection of Chinese people to characters (square signs), or, on the contrary, it is that square writing sets the Chinese phonetic into the frame of synthetic acoustic units like toned syllable, but perceiving articulated signs now, Chinese native speakers demonstrate a strong intention to make any sequence of signs meaningful. This intention is obvious in ways Chinese people adopt names of foreign brands into Chinese - usually they transcribe it, but always choose characters not only close by pronunciation - but also those which contain association with the brand on the level of meaning.

Let us take the name of the brand Tissot as an example (Figure 8). It was presented in Chinese through two syllables - 天梭 (tian suo), which made a comprehensible phrase together, meaning "a sky shuttle", where "shuttle" evokes an association with a mechanism, and together with the epithet "sky" it looks like an ideal mechanism. Though there is not a direct or obvious (visible) resemblance between "a shuttle" and "a watch," they can belong to one category of things through an indirect association, based on the functional (not formal or visible) resemblance. That is why these two characters (天 and 梭) were chosen for transcription of the foreign name Tissot - because they are not only very close by pronunciation, but also associated with the object of advertisement by meaning.

Figure 8. Commercial Issue Ad

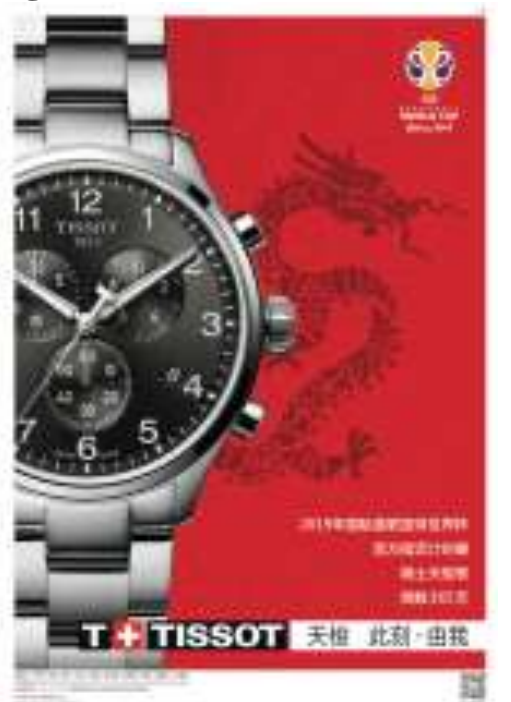

Source: https://bkimg.cdn.bcebos.com/pic/c8177f3e6709c93d5c0dbf93913df8dcd00054d2?x-bceprocess=image/resize,m_lfit,w_153,limit_1

The same logic is used in all other cases of translating advertisements and transcribing names of brands. In other cases, if "empty" (not meaningful) signs were used, the new words would not evoke any idea in the minds of Chinese speakers, so they might hardly remember it and buy the product. In Chinese culture 
based on characters, names should be meaningful and create images to be noticed and remembered.

In Japanese we can rarely see the same way of the characters' usage as the names of foreign brands are created with the katakana alphabet. Acoustic modality is observed in the form of "fuzake-yomi" - sound-play of characters combined for fun or for making associative puns of words. For example, for the arithmetic operation of multiplication, a combination 八十 一 (lit. "eighty-one") was used and it was supposed to be read "kuku" (repeating the number 9, so that the reader could guess that it is a hint for 9 x $9=81$ ), 十六 (lit. "sixteen") - "shishi" (repetition of the figure $4,4 \times 4=16$ ). Onomatopoeia was also used for a wordplay or even a "character-play": in a certain context a syllable む "mu" was expressed in writing by characters 牛鳴 (lit. “mooing of a cow”), ぶ “bu” - 蜂音 (lit. "buzzing of a bee") (Sudo 2006, pp. 25-29).

So, we can see that a character is not "dumb," it becomes a knot, where a particular meaning ties with a particular group of sounds (by acoustic association) and creates the acoustic modality in this way. Promoters of foreign goods in China should take this into consideration if they want to be successful in the Chinese market.

Tones as an extralinguistic and non-linear phenomenon in Chinese phonetics opens a way for a musical dimension in the Chinese language. From the point of view of articulation, tones come from manipulations of air flow during exhalation, and because of that, to pronounce a tone, the speaker must control his/her breathing - just like he/she does when searching for his/her own inner center in the process of writing characters.

Tones evoke a sense of rhythm in Chinese speech, which correlate with the sense of symmetry, produced by quantitative characteristics of text written in characters. Two modalities (vestibular and audial) are naturally coordinated in the process of reception.

Then, it is proposed in this paper to look at Chinese characters from another point of view: depicting objects or situations schematically, they borrow their forms from them and are figures due to their shapes (unlike letters in phonetic alphabets).

\section{Vestibular Mode of a Character}

If we use the terminology, proposed by McLuhan and Powers (1989), we can say, that as a figure, any Chinese character needs a ground - a space, it is situated in. Usually it is a square of the same size for all characters in a particular text, which makes any text in Chinese potentially highly symmetrical (this potential is very often realized in poetry). We propose to consider that this square ground is a source of a vestibular modality, as it demands to orient all strokes of a character by its (square) axes and direct these axes to the center of a character (which usually tends to be slightly moved to the bottom left corner in comparison with the center of the square), and this compositional demand is supposed to give a sense of stability and unity of a character for its reader. This can be illustrated by the 
character 立(to stand, Figure 9), which conveys the sens of stability even through its visual form, not only verbally.

Figure 9. The Character "Stand" in its Square "Ground"

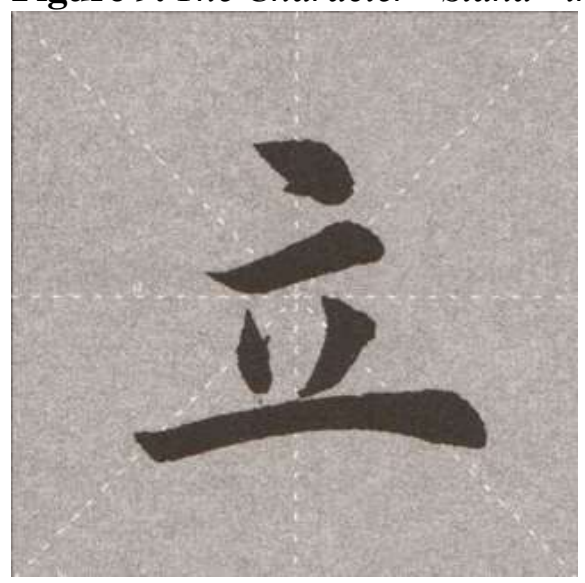

Source:https:/gimg2.baidu.com/image_search/src=http $\% 3 \mathrm{~A} \% 2 \mathrm{~F} \% 2 \mathrm{Fs} 1$.sinaimg.cn $\% 2 \mathrm{Fmw} 690 \% 2$ F001IJShTgy6O9qMSdos70\%26690\&refer=http $\% 3 \mathrm{~A} \% 2 \mathrm{~F} \% 2 \mathrm{Fs} 1$.sinaimg.cn\&app=2002\&size $=\mathrm{f} 9$ 999, $10000 \& q=a 80 \& n=0 \& g=0 n \& f m t=j p e g ? s e c=1625597837 \& t=d a 29$ dea0c24f2f1 1 ef61d92b414e 8 603

Thus, the writing of Chinese characters is usually an experience of searching for a balance of the writer's own inner center, which usually involves the personal vestibular experience of a writer. Reading the characters also allows a reader to recreate this experience. Chinese calligraphy is known as an exercise of breathing as well, because to write a character in a proper way, we need to balance our inner world, and in a case of failure to reach that balance, a recipient may see it as an orthographical mistake. This is why we propose to call this mode of existence of a Chinese character (and a Japanese one also) a vestibular modality.

The main effect, produced within this mode, is a high sense of symmetry - an extralinguistic phenomenon, generated in this case by the linguistic unit (as letter signs belong to linguistic signs).

Except in old Chinese poetry, which was highly symmetrical for reader's eye, this effect is also used in modern advertisements. For example, one of the slogans of L'Oreal - The World Needs Beauty - was translated into Chinese in this way: 创新美丽, 生生不息

A word-by-word translation from Chinese would be, "Creating beauty (should be) endless." Such a translation is not equivalent, but it is creative and attractive at the visual level (as shown by its content) because this content is put into a phrase divided into two parts of four characters each. This equivalent quantity produces the effect of symmetry and makes the slogan more attractive for readers (consumers).

This sense of symmetry and stability is very important for road signs also, like it is shown in Figure 10, making them "easily-followed." It is worth noting that there are a lot of road signs in China and Japan written in characters, rather than depicting non-verbal symbols. 


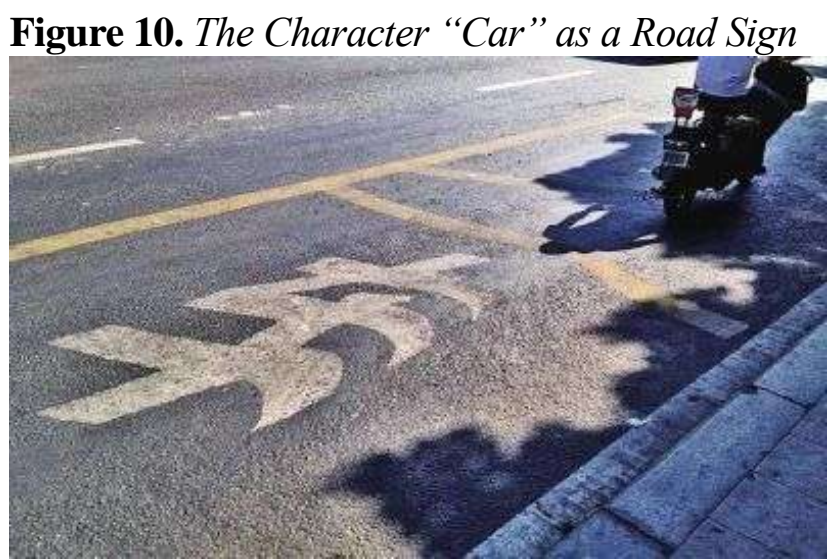

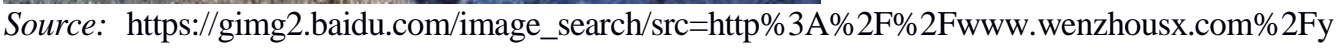
ujeu\%2Fwenzhou\%2F1308\%2F993_130807154906_1.jpg\&refer=http\%3A\%2F\%2Fwww.wenzho usx.com\&app $=2002 \&$ size $=\mathrm{f} 9999,10000 \& \mathrm{q}=\mathrm{a} 80 \& \mathrm{n}=0 \mathrm{Q} \mathrm{g}=0 \mathrm{n} \& \mathrm{fmt}=\mathrm{jpeg} ? \mathrm{sec}=1625124852 \& \mathrm{t}=3 \mathrm{a} 1 \mathrm{e}$ $4 \mathrm{f} 72 \mathrm{fc} 32 \mathrm{c} 748947 \mathrm{a} 5 \mathrm{a} 5 \mathrm{dd} 4 \mathrm{f} 6986 \mathrm{f}$

\section{Conclusion}

Thus, we can see that any Chinese and Japanese character exists in three dimensions simultaneously and generates three modalities at the same time. Its correspondence with morphemes opens two channels for encoding information first of all, it brings a space for audial modality through the acoustic form of a syllable, and then it opens a space for visual modality through the graphical form of a character. The latter form implies a space for vestibular modality, because as a "figure," any Chinese character occupies its "ground" (a particular square area), which becomes a source of a sense of stability and symmetry, enriching linguistic message with non-verbal information. However, it should be also noticed that it depends on the situation if all three modalities will be "in-use." Most people use their language as an instrument to exchange information in everyday life, and under these circumstances they prefer to avoid any extra information (like searching for their inner center, for example), which can slow down or even break up the line of circulation of information. But when the language is used with aesthetic purposes, this extralinguistic information, hidden in different modalities, generates value and affects the recipient of information on different psychological levels - the cognitive, emotional, and motivational.

So, any text written in characters should be considered as verbal, visual and vestibular at the same time, and the history of Chinese writing system shows that characters had been developed from image to scheme, from depicting a situation to recording a language.

In other words, there was a precedent in the history of processing information when the image dominated messages and linguistic texts. There is a writing system (Chinese and Japanese characters) in which images still dominate, but it developed to reduce the visual mode and increase a verbal (audial) one.

From this point of view, the audial mode of transmitting information seems to be mostly exact, while images, though capacious from the point of view of 
information, are rather ambiguous for understanding and open a wide space for the recipients' imagination. It is a valuable capacity for aesthetic use, but it interferes with other spheres of communication which need more strictness in processing information. The Chinese writing system demonstrates this logic by putting images in the service of words during its more then 5,000-year development, and this logic was followed by Japanese, when inventing their own writing systems.

\section{References}

Alpatov V (2003) Yaponiya: yazyk I obschestvo (Japan: language and society). Moscow: Muravey Publishing house

Doblhofer E, Friedrich Y (2002) Istoriya pisma: evolyutsiya pismennosti ot Drevnego Yegipta do nashikh dney (The history of writing: evolution of writing from the Ancient Egypt till nowadays). Moscow: Eksmo, St Petersberg: Terra Fantastica.

Guder A, Xin J, Yexin W (Eds.) (2007) The cognition, learning and teaching of Chinese characters. Beijing: Beijing Yuyan Daxue Chubanshe.

Hanzi W (2009) Five thousand years of Chinese characters. Beijing: Xinxing Chubanshe.

Ivanov A, Polivanov Y (2007) Grammatica sovremennogo kitayskogo yazyka (Modern Chinese grammar). Moscow: Izdatel'stvo LKI.

Kress G (2011) Multimodal discourse analysis. In The Routledge Handbook of Discourse Analysis, 35-50. Routledge.

Luo J (2011) Hanzizhongde shenti mima (The body code in Chinese characters) Shanghai: Dongfang Chuban Zhongxin.

Lyons A (2016) Multimodality. in Zhu Hua (ed.), Research Methods in Intercultural Communication: A Practical Guide, 268-280. Wiley-Blackwell.

Mayevskiy E (2000) Graficheskaya stilistika yaponskogo yazyka (Graphical stylistics of the Japanese language). Moscow: Muravey-Guide Publishing House.

McLuhan M, Powers B (1989) The global village: transformations in world life and media in the 21st century. New York, NY: Oxford University Press.

Obara T, Okazawa A (Eds.) (2011) Nihon no moji (Japanese letters). Tokyo: Kabushiki Gaishya Popurashya.

Rezanenko V (1989) Semanticheskiye elementy znakov iyeroglificheskoy pismennosti (Semantic elements of signs in the hieroglyphic writing). Kiev: UMK VO.

Sudo K (2006) Yaponskaya pismennost ot istokov do nashikh dney (Japanese writing from the beginning till nowadays). Moscow: AST: Vostok-Zapad.

Wieger S (1965) Chinese Characters: their origin, etymology, history, classification and signification. A thorough study from Chinese documents/Translated into English by L Davrout. S.F. - N.Y.: Paragon Book Reprint Corp.; Dover Publications, Inc.

Xu S (2009) Yuyan wenzi (Language and writing). Nanjing: Nanjing Daxue Chubanshe.

Zhang J (2010) Yuyan renzhi xinlun: yizhong xiangduilunde tantao (A new theory of cognitive linguistic: a discussion from the relativity point of view). Guangzhou: Guangdong Gaodeng Jiaoyu.

Zhao Y (2002) Yuyanxue lunwenji (Collected works in linguistics). Beijing: Shangwu Yinshuguan. 